\title{
AN ETHICAL CASE STUDY: CASTRATION OF PIGLETS WITHOUT ANESTHESIA
}

Amanda Whitfort, Associate Professor, Faculty of Law, The University of Hong Kong

\section{SUMMARY}

I. The Concern with Castration

II. Ethical Theories and Options for Legislators
A. Utilitarianism
B. Animal Rights
C. Contractarianism

III. Conclusions 


\section{THE CONCERN WITH CASTRATION}

According to EUROGROUP FOR ANIMALS more than 100 million male piglets are castrated in the EU every year, most without anesthetic (Eurogroup 2014). Eurogroup for Animals have lobbied to have surgical castration of piglets banned by legislation but to date have not been successful. Surgical castration without pain relief is permitted in the EU if the animal is less than 7 days old. The European Commission has succeeded however in securing a voluntary agreement with major stakeholders in the pig industry ${ }^{1}$ which has required analgesia/anesthesia for surgical castration at any age since 1 Jan 2012 and provides that castration should cease entirely by 1 Jan 2018. The European Declaration on Alternatives to Surgical Castration of Pigs relies on scientific opinion in support of its aims.

The Opinion of the Scientific Panel on Animal Health and Welfare of the European Food and Safety Authority (EFSA 2004) on the welfare aspects of castration of piglets found that physiological and behavioural reactions of piglets indicative of pain are numerous during the process and in the first hours following surgical castration without anesthesia. While these reactions decrease thereafter, some behavioural alterations persist for days. The Panel found that available evidence suggested castration of piglets was a painful and stressful event and that the use of local anesthesia offered the best practical prospects for pain alleviation.

Whilst the primary reason for the castration of male piglets is to prevent boar taint in their carcasses, the EFSA Opinion also supported the widely held view

\footnotetext{
${ }^{1}$ Signatories to the European Declaration on Alternatives to Surgical Castration of Pigs include farmers, breeders, animal welfare groups, retailers, scientists and veterinarians. The Declaration is available on the European Commission's website at http://ec.europa.eu/food/animal/welfare/farm/initiatives_en.htm [Accessed: 14 February 2014].
} 
that castration results in less aggression and calmer animals during fattening. Castration thus provides an effective method to manage the confinement of the pigs and profit from their meat.

As reported by PigProgress News (2014), concern has been expressed by the director of Eurogroup for Animals as to whether the incoming 2018 voluntary prohibition brokered by the European Commission will be enough to protect piglets from castration without anesthesia. There has been a suggestion by the Federation of Veterinarians of Europe (FVE), amongst others, that a Directive should be issued to ban castration without anesthesia across the EU (FVE 2009).

Resistance to such a ban primarily results from the extra cost incurred to farmers if anesthetic and veterinary services are required at castration. While the costs of castration could be avoided completely, fear of boar taint precludes most farmers from raising entire animals.

\section{ETHICAL THEORIES AND OPTIONS FOR LEGISLATORS}

In this paper I use the ethical theories developed by utilitarians, animal rightists and contractarians to evaluate whether a legislative prohibition on the castration of piglets without anesthesia should be introduced across the EU. Even assuming that the EFSA Opinion is entirely accepted by all parties to the debate, it will be seen that depending on which ethical theory is supported by policy makers, different legislative outcomes could result.

\section{A. Utilitarianism}


According to the classical version of this theory, the morally right action is the one which brings about the greatest possible amount of happiness, where happiness is the balance of pleasure over pain (Gjerris, Neilsen and Sandoe, 2013, p.91). For Singer (2004, p. 80), in determining the moral utility of an action, animal and human interests are counted as equal, where there is evidence of sentience. This theory would thus give the same consideration to the happiness/pain experienced by a pig as to that experienced by a human being.

In determining whether castration of piglets without anesthesia is ethically acceptable, the utilitarian approach requires the pain suffered by the piglets to be weighed against the benefit to farmers in castrating without pain relief. It is a basal interest of animals to avoid pain and suffering. However, if pain relief is required by law, farmers will be required to undertake the costs associated with purchasing medical supplies and veterinary services. A policy maker, determining whether to introduce a prohibition on castration without anesthesia, must determine whether the interests of the piglets or the humans should be prioritised.

Of course, castration with anesthesia is not the only way for farmers to minimize the risk of boar taint. There are alternative methods of castration used outside the EU, such as immunocastration, but the expense to farmers would still be more than castration without pain relief. As reported in a guest blog by $\mathrm{Dr}$ Steven McOrist on PigProgress (2006), possible complications with immunocastration may include injection site lesions, needles snapping off in pigs, logistical problems with giving the booster dose to near slaughter weight pigs and the risk of self- injection to human handlers, although in Australia, where the vaccine is widely used, such problems are reported to be rare. In evaluating the vaccine, Prunier et al., (2006) also noted that consumers may be wary of the risk of residues in the meat. 
Were a prohibition imposed, farmers could avoid the extra expenses and risks involved by leaving their pigs intact. While some farmers in the EU do raise entire pigs, for many the risk of producing pork with boar taint makes the option unacceptable. A further consideration for the industry, if pigs are left intact, is the expense involved in removing tainted carcasses from the fresh pork supply. The EFSA Opinion also identified a welfare risk to the pigs if they are left intact, due to the increased likelihood of social stress and aggression. As a result, the animals may suffer skin lesions and their carcasses may be damaged. While the potential for undesirable behaviours may be reduced by better husbandry practices; more staff monitoring and provision of larger housing, the costs involved would make this requirement unpopular with farmers.

In determining where the maximum utility lies, the interest of the piglets in not suffering a painful procedure that may negatively impact on their welfare for days would arguably outweigh the interest of human beings in avoiding the cost of providing medical services for castration. The financial burden placed on farmers, were a prohibition put in place, would necessarily be factored into the equation but the choice is also open to those farmers who wish to avoid the financial cost of providing anesthesia, or even immunocastration, to abandon castration altogether. The benefit to the piglets in avoiding a painful procedure would seem to outweigh the benefit to the farmer in ensuring all his pigs remain free of boar taint. The farmer may maximize his profit if all his meat is free of boar taint but that would not seem sufficient to tip the balance in his favour.

While the need to protect the animals from undesirable behaviours and possible harm from one another would also need to be considered, the risk of some animals potentially causing suffering to one another, if they are left intact, would be weighed against the certainty that they will all suffer if they are castrated without pain relief. The necessary expense involved to the farmers in requiring additional staff for the monitoring of aggression and intervention would again 
seem a less weighty concern than the routine infliction of pain to 100 million piglets per annum if a prohibition on castration without anesthesia is not introduced.

Even expanding the evaluation of human interests beyond the pig industry to the community at large, the piglets' interests arguably trump the humans. Whilst it makes economic sense for the industry, it is not strictly necessary for all the pork available on the market to be completely protected from the risk of boar taint. Humans need not eat pork to survive. In most cases they only do so because they like the taste. Their welfare is not seriously compromised by avoiding the consumption of pork for the risk it has boar taint and the animal interest should therefore trump the human (Singer, 1993, p.63).

On the balance of interests, the negative welfare impact on the piglets would therefore require the utilitarian to reject castration without anesthesia and demand a prohibition on the practice.

\section{B. Animal Rights}

Like utilitarianism, the animal rights position also presupposes that animals have moral status. But animal rights requires more than equal consideration. It imposes on humans direct duties towards other animals. Whilst the extent of those duties is debated within the animal rights movement, the right of all animals not to be harmed is considered fundamental (Regan, 1983, p.287). Practices which flout this right would therefore be considered unethical. As such castration of piglets would be unethical as it harms the animal by causing suffering and interferes with the animal's bodily integrity. For many animal rightists, the domestication of animals and the killing of them for food are also breaches of animals' fundamental rights to freedom from captivity and to life. 
The purpose of castration being to prevent boar taint in the carcass and to produce more docile animals during confinement, the practice in its wider context also violates an animal's right to be free from captivity and to life.

The animal rightists concern with the castration of piglets cannot be defeated by a legal requirement to use anesthetic. While the use of pain relief would allow the animals to be protected from the harm of a painful procedure without pain relief, it would do nothing to address the harm caused by interfering with the piglets' bodily integrity. The use of immunocastration similarly fails to pay due regard to bodily integrity. Further, the primary reason for the practice of castration, however it is achieved, is to render the animal's meat more attractive for human consumption after death. The practice therefore accords no value to the right to life. Rather the animals are treated as a resource for humans. They are kept in confinement for human ends and killed before their natural time.

Even taking into account the paternalistic benefits to pigs which arise from castration, (it reduces the chance they will suffer aggressive behaviour from others in their group), the fact remains that these so called "undesirable" behaviors would not be a problem for the animals if humans were not closely confining them. Animal rightists also claim that even the significant economic benefits to humans which are derived from the industry cannot justify the violation of farm animals' rights. As argued by Regan (1983, pp.345-6), the humans' right to profit from farming cannot legitimately ride on the back of a violation of others' rights.

It would therefore seem impossible for a policy maker to satisfy this group whatever decision is reached on castration without pain relief. Castration with or without anesthesia would fall foul of the requirement to take into account the fundamental rights of the pigs to bodily integrity, freedom from captivity and the right to life. Immunocastration would suffer the same criticisms. It is important to recognise though that some advocates of animal rights may support the 
prohibition of castration without anesthesia from a practical standpoint. While the hard line abolitionist would certainly resist the prohibition on the basis that it assumed some non existent ethical justification for keeping the pigs in captivity (Francione, 2000, p.17), the pragmatist may well accept the prohibition as a first step towards the ultimate goal of providing animals with enforceable rights against dominion by humans (Favre, 2004, p.236). While freedom from captivity would not be achieved by the prohibition, protection from pain, (in one particular context), could be achieved if a prohibition on castration without anesthesia were adopted. As such the policy maker may find support for the prohibition within the less hard line pragmatist animal rights camp.

\section{Contractarianism}

This theory provides that morality is the result of an imaginary contract between rational agents who have agreed upon a set of rules to govern their subsequent behavior (Carruthers, 1992, pp.36-37). As animals are not rational agents they cannot "contract" with humans to benefit social cohesion as they cannot engage in long term planning, abstract thought or be held accountable under society's rules. Thus they have no moral standing under the theory. Rawl's theory of justice similarly did not extend to animals but it did suggest humans had a duty to treat other animals with compassion in recognition of their ability to experience pleasure and pain (Rawls 1972).

As piglets have no moral standing, contractarianism would, prima facie, permit the castration of piglets. Castration could even be viewed as desirable as it reduces the likelihood of both boar taint and aggressive behaviour between pigs; making husbandry practices less costly (both in terms of numbers of persons required to manage the animals on farm/during transport/at slaughter and the need for extra housing space). Of course even if castration is ethically 
acceptable it is another question entirely whether anesthesia should be required before castration. As noted by Gjerris, Neilsen and Sandoe (2013, p.83) while the contractarian view does not require that we take into account unnecessary animal suffering, it suggests that we should do so, if some people would prefer that we did

The fact that the European Commission has taken steps to secure the voluntary agreement of major stakeholders in the pig industry to use analgesia/anesthesia and even end surgical castration entirely by 2018 , demonstrates that for many people this is a real concern. The contractarian view requires that where some people prefer a course of action, their views should be taken into account. So while anthropomorphic in bias, this ethical theory would not simply allow the industry's desire for maximum profit and the public desire for reliable tasting pork to dictate that no prohibition on castration without anesthesia should be enacted in law. On this view, the preferences of those humans that are concerned about animal suffering would also need to be taken into account by the policy maker before any decision on the need for prohibitive legislation could be reached.

It is also worth mentioning that there have been some attempts to extend the contractarian view to give moral standing to animals. Rowlands has suggested that Rawl's theory be extended to include all sentient beings as beneficiaries under the veil of ignorance (Rowlands, 2009, pp.163-165). He argues that if animals were given moral standing then we could not eat them. It would not be a rational choice to accept the raising of animals for food if there was a chance you might find yourself born one of those animals. If the eating of animals is immoral, the same would apply to castration without pain relief.

III. CONCLUSIONS 
Depending on which ethical theory is adopted as policy, different responses to the dilemma may result. The moral case for prohibiting castration without anesthesia, in the interests of preventing unnecessary animal suffering, is certainly strong. Against this rests the financial interests of members of a large industry. The legislator faces a dilemma that could perhaps best by resolved by an appeal to impartial science. That is certainly the stance adopted by Eurogroup for Animals, which relies heavily on the EFSA findings to advance their cause. It is important, however, that we remain cognizant of the fact that ethical assumptions do underpin objective scientific findings (Sandoe, 2012). Despite the specific mandate of the EFSA, a hedonistic view of the need to avoid animal pain, even where this would limit natural behaviors, has clearly influenced their opinion on the welfare aspects of piglet castration. Such ethical assumptions might well be justified, but they should also be made transparent. 


\section{REFERENCES}

CARRUTHERS, P. (1992) The Animals Issue: Moral Theory in Practice. Cambridge: Cambridge University Press.

EFSA SCIENTIFIC PANEL ON ANIMAL HEALTH AND WELFARE OPINION (2004) Welfare Aspects of the Castration of Piglets. The EFSA Journal 91:1-18.

EUROGROUP FOR ANIMALS (2014) Pig Castration [Online] Available from: http://eurogroupforanimals.org/what-we-do/category/farm-animals/pig-castration [Accessed 14 February 2014].

FAVRE, D. (2004) A New Property Status for Animals: Equitable Self Ownership. In SUNSTEIN, C. and NUSSBAUM, M. (eds.) Animal Rights: Current Debates and New Directions. Oxford: Oxford University Press.

FEDERATION OF VETERINARIANS OF EUROPE (2009) Pig Castration Position Paper.

[Online]

Available from:

http://www.fve.org/news/position papers/animal welfare/fve 09040 castration pigs 2009.pdf [Accessed 14 February 2014].

FRANCIONE, G. (2000) Introduction to Animal Rights: Your Child or the Dog? Philadelphia: Temple University Press.

GJERRIS, M., NIELSEN, M. E. J. and SANDOE, P. (2013) The Good, the Right and the Fair: An introduction to ethics. Texts in Philosophy Volume 22. United Kingdom: College Publications. 
PIGPROGRESS BLOG (2006) Some comments on immunocastration. [Online] Available from: http://www.pigprogress.net/Home/General/2006/12/Somecomments-on-immunocastration-PP002041W/ [Accessed 14 February 2014].

PIGPROGRESS NEWS (2014) Eurogroup for Animals: "Castrating pigs is utterly unnatural"

[Online] Available from: http://www.pigprogress.net/Breeding/WelfareEnvironment/2014/1/Eurogroup-for-Animals-Castrating-pigs-is-utterly-unnatural$1440362 \mathrm{~W} /$

[Accessed 14 February 2014].

PRUNIER, A., BONNEAU, M., von BORELL, E. H., CINOTTI, S., GUNN, M., FREDERIKSEN, B., GIERSING, M., MORTON, D.B., TUYTTENS, F. A. M. and VELARDE, A. (2006) A review of the welfare consequences of surgical castration in piglets and the evaluation of non-surgical methods. Animal Welfare, 15: 277-289.

RAWLS, J. (1972) A Theory of Justice. Oxford: Oxford University Press.

REGAN, T. (1983) The Case for Animal Rights. London: Routledge and Kegan Paul.

ROWLANDS, M. (2009) Animal Rights ( $2^{\text {nd }}$ edition). United Kingdom: Palgrave Macmillan.

SANDOE, P. (2012) The interaction of ethical questions and farm animal welfare science. Paper presented at Animal Welfare and Ethics: From Principles to Practice, RSPCA Australian Scientific Seminar, 28 February 2012, National Convention Centre, Canberra, Australia. 
SINGER, P. (1993) Practical Ethics (2 ${ }^{\text {nd }}$ edition). New York: Cambridge University Press.

SINGER, P. (2004) Ethics Beyond Species and Beyond Instincts: A Response to Richard Posner. In SUNSTEIN, C. and NUSSBAUM, M. (eds.) Animal Rights: Current Debates and New Directions. Oxford: Oxford University Press. 